\title{
Territorialized Production Forms in Morocco: Provisional Assessment for an Own Model in the Pipeline
}

\author{
Oumhani Eddelani \\ Faculty of Economics and Law, Sidi Mohamed Ben Abdellah University, Fez, Morocco
}

\begin{abstract}
With the recent "glocalization" movement that is imposed by openness to the global sphere and the necessary anchoring to the local, the productive systems - from here and elsewhere - can no longer be a-territorial or autarchic. As much as openness opens the competitiveness prospect, so much does the local territory assure a sort of "safety net" and refuge in case of global crises that have become frequent. Whether it is the paradigm of social movement or the canvas of a local production system, "glocalization" is justified by the potential for wealth that the territories of any nation seeking its international competitiveness conceal. In order to identify, understand and value this territorial resource, the diagnosis of the existing is essential. Sociospatial disparities are the core problems of regional development which is confronted with the double malaise of poverty and environmental degradation. Knowing that wealth is created within companies and that these businesses are the key players in territorial development, the analysis of the spatial anatomy of productive systems provides information on the symbiosis between the productive and the spatial.Without claiming to reproduce the evolution of productive systems and their spatial expressions in its completeness, this study aims at questioning the major territorialized forms that the productive system in Morocco has taken ever since their independence. It also aims at characterizing the specificities of Morocco in this area by launching a particular provisional assessment of the fact that this experience is maturing. The main objective of this research is to approach a model that is in the making in which Morocco can lead the rest of Africa at this spatial / productive level.
\end{abstract}

Keywords: Productive system, territorialized forms of production, glocalization, Integrated Industrial Platform (P2I), Clusters, Territorial Pole of Economic Cooperation (TCEP), Localized Production System (LPS).

DOI: $10.7176 / \mathrm{JAAS} / 53-06$

Publication date:March $31^{\text {st }} 2019$

\section{Introduction}

The various territories that include the nations present an unavoidable resource for the States that wish to better position themselves in the world competition, especially in an international context where the industrialist and the space interlock. If Western researchers (American, Canadian, French, Italian ...) have become aware of this "niche" for almost half a century, in the south - including Morocco - this rediscovery and / or recurrence of the territory goes back only to ten years. In fact, a serious analysis of the spatial expressions of the productive process in Morocco coincides with the famous analysis on the SPL and the territorial competitiveness in 2002 recommended by the Directorate of Planning. Workshop where the first premises were already prepared with the 1997 regionalization and the national debate on regional planning. With the sphere of off shoring and new directions of industrialization, the spatial variant becomes vital in the race for the attractiveness of domestic and foreign investments via territorial marketing maps of cities, regions and localities.

The economic mobility that Morocco is experiencing makes it an open project at all levels. In terms of the spatio-temporal organization of the productive system, we have moved from industrial districts to what the National Pact for the Industrial Emergence, "NPIE" calls "P2I" or integrated industrial platforms. Casa Nearshore, Rabat Technopolis, Meknes Agropolis , Fez - Technovalley, Tanger Free Zone ... This trend is prolonged by the Industrial Acceleration Program (IAP) and so-called "clusters" which act as expressions of a spatial anatomy that attests the new dynamism experienced by this cosmopolitan country.

In this vein, this paper aims at questioning these P2I as territorial expressions of the productive organization by putting them under analysis and investigation in order to be able to compare them with other forms such as clusters, SPL or others. Two axes will, then, articulate our communication, the first one is dedicated to the presentation of the new Emergence and NPIE programs by questioning if this last one constitutes the continuity or the rupture of the first one. The second one deals with their spatial and territorial anatomy while looking for whether there is an overall coherence leading to a thoughtful development of our open economy on different actors of the international economy.

\section{1- productive and spatial restructuring in the North}

In countries with a capitalist tradition, two salient features are worthy of mention : At the level of productive systems: the progressive transition from Fordism to flexibility. At the spatial level: The decline of industrial cities and the rise of territorialisation of production. 


\section{1- Productive restructuring, rigidity and flexibility}

The principles and logic of Taylorffroyism as a system of accumulation and as a system of industrial organization are interconnected. Mass production requires mass consumption to allow the flow of products. Indeed, born in a specific macroeconomic context, the Fordist system was the main micro-economic engine of globalization in the 1950s and 1960s. However, the 1970s marked the end of monopoly regulation. As an industrial organization system, its strengths become weaknesses. As a mode of social regulation, the wage relationship that it underlies has broken down. The rigidity of Fordism becomes anti-productive and gradually gives way to the flexibility of which the Japanese system constitutes a typical example of illustration.

In general, flexibility is "the ability to adapt in the short term to hazards" (Veltz - 1996).

The flexibility of an industrial system is defined as its "ability to train to improve its insertion into the environment and increase its chances of survival. The flexibility of an industrial system consists in its capacity to modify the composition and the volume of the inputs, to adapt its means and method of transformation and to modify the nature and the volumes of the products and services offered to the markets "(Tarondeau - 1993).

For A. Scott and M. Storper, "the current period, that of the crisis of Fordism as a capitalist accumulation regime, leads to the emergence of a new regime of flexible accumulation" (Scott\& Storper -1998). For A. Ficher, "the search for and the generalization of greater organizational, structural and functional flexibility is, perhaps, one of the major responses to the crisis of the Fordist productive system"(Fisher - 1998).

The debate on flexibility is therefore linked to the controversy over globalization, the role of the state and the stability of the dynamics of productive structures. It can be functional, technical, financial or digital.The Toyotist industrial system presents an illustration. According to Tarondeau, it is "the absolute weapon of the economic war. It is the industrial system that uses less than anything: half the time and effort required to design the product, half the labor and tools to achieve it, half less defects and less half of stock » "(Tarondeau - 1993).

But creative flexibility remains to be done. It is therefore only a social compromise of globalization. In sounding the death knell of Tayloro-farsity both as a system of accumulation and as a system of industrial organization, globalization requires a flexible enterprise alone capable of coping with the demands of postFordism.

\section{2-Restructuring of productive systems does not leave spaces and territories untouched}

Globalization makes competitiveness and flexibility a work of businesses, economies and territories alike. Why the revenge of the local?

For R. Kohen, this revenge is due to the relevance of the local economic action having three bases:

- The local has a "good command of information and the ability to mobilize the will in the field";

- The local territory is also able to "animate local networks of economic and social relations";

- Finally, as part of the current process of "glocalization" symbolized by the saying "think globally, act locally", the local animators (economists and geographers) suggest that the local level is as important as the global to understand and promote the current economy.

\section{What is an LPS?}

The concept of SPL derives from that of the industrial district. The latter identifies with A. Marshall, who defined it since the 19th century as "a socio-territorial entity characterized by the active presence of a community of people and a population of companies, in a given geographical and historical space". (Benko \& Lipietz 1993). For G. Beccatini, "a perfect osmosis between local community and companies". It is a typical form of territorialized productive industrialization that the French call SPL. An LPS is a particular productive organization located in a territory that generally corresponds to a pool of employment. It functions as a network of interdependencies consisting of productive units, having similar or complementary activities and dividing the work

An SPL is therefore a set:

$\checkmark$ enterprises producing goods and services;

$\checkmark$ research centers;

$\checkmark$ training organizations;

$\checkmark$ Technology transfer and monitoring centers ...

who maintain between them different relationships of more or less intensity (formal and informal, merchant and non-commercial, material and immaterial ...)

An SPL is then characterized by:

- A spatial concentration of SMEs;

- Specialization around a trade or a product;

- Co-operation / competition or simply a strong business-to-business cooperation relationship;

- Access to a set of market and non-market services;

- In the end the sharing of a common culture. 


ISE

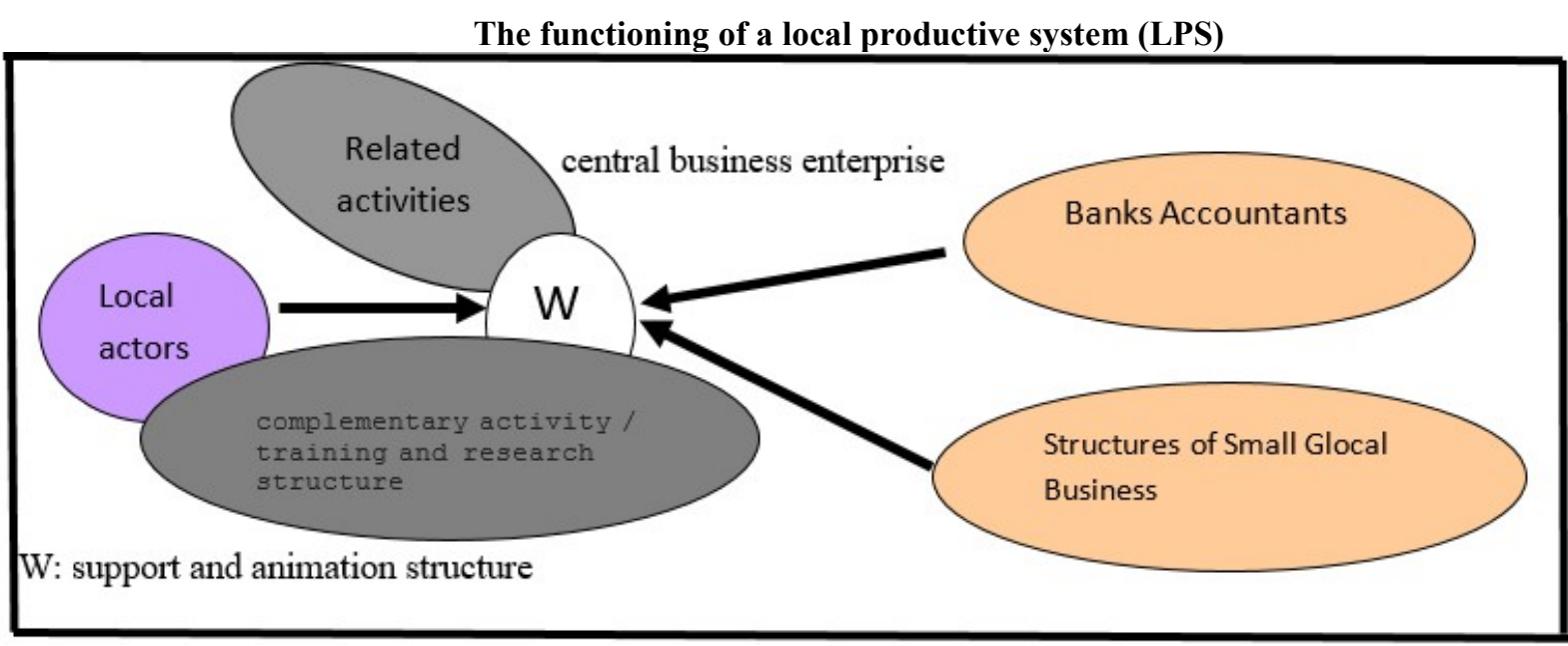

Source : P. Pommier, $p: 5$

SPL actors are: The company as a key player ; training organizations as gray matter producers ; Research centers (strategic actor) ; Major industrial groups as sponsors ; The State, political actor and the region, partner actor.

In these conditions, a new economic geography emerges, one that Veltz calls the economy of the "zebra" or international mosaic, but where SPL are of great importance both in the industrialized countries and those in the process of development. Short, the concept of SPL is becoming an international language spoken everywhere. It is an analytical category tending to universalism. Globalization has broken the coincidence between the area of economic management of accumulation and that of political and social management. (S. Amin 1997). The flexible glocal enterprise and the SPLs become key players in the Fordist crisis.

Concerning Morocco, we can announce that through the "democalisation" (PAS), the investment code, the PNZI, the SNAT and regionalization, the geography of the production remains a creation ordered by the logic of State and not private. However, with the flexibility and the challenges of globalization and regionalization, consistency with the logic of the global production system becomes an obligation.

Having a context of evolution proper, the productive system of Morocco has not known (strictly speaking) the transition from Fordism to flexibility. However, the challenges of a spatial organization aiming at more territorial competitiveness are still there. How does Morocco manage the report "opening on the global anchorage to the local"?

\section{Emergence Plan (EP) - National Pact for Industrial Emergence (NPIE) - Industrial Acceleration Plan \\ (IAP): continuity or rupture?}

The challenge that is facing Morocco's openness is to increase the competitiveness of its economy, to transform potential risks into opportunities, and finally to erect the country into a regional investment-production-trade platform, and promote its attractiveness and powerfulness at the crossroads of Europe, the Maghrebian, African and Mediterranean space. The plans: PE (2005), NPIE (2009) and industrial acceleration (2014) are part of this spirit.

(Due to the lack of academic writing on these aspects, we emphasize that in this section, we rely mainly on the Mckinsey report, on the full text of the NPIE, on the presentation that was delivered by the the industry and finance ministers at the time (respectively Chami \& Mezouar ) as well as what was reported in the print media and the national media, including analyses and interpretations.)

\section{1- The main features of the Emergence Plan}

In the 1990s, Morocco had just emerged a long and an excruciating Structural Adjustment Program (SAP) and showed new ambitions: reconquest of markets, economic takeoff, competitive industry. Under these conditions, the World Bank recommends setting up a development monitoring committee whose mission is to define a strategy that will endow Morocco with a modern and a competitive industry. The committee makes their copy with a strategy which is called "Morocco Competitive", built around clusters, sectors that are supposed to play the role of locomotive to foster growth. It is, then, necessary to create wealth and ensure the return of foreign currency; hence the slogan of "Emergence". The 2005 PE focuses on two areas: creating wealth, therefore employment and growth; and developing high added value export activities.

McKinsey (CESE - 2009) cites, however, a certain set of handicaps: the importance of the informal sector, the weakness of domestic demand, the dependence of the economy on a scattered, highly undercapitalized industry, the heaviness of administrative procedures, taxation and business regulation, etc. 
These pitfalls are more pressing in so-called second-tier regions. The upgrade of the Moroccan company then intervenes as a means to face the opening as well as a necessity, an opportunity and a challenge.

The Emergence Plan (EP) was based on a proactive but not exclusive targeting of growth drivers and the competitive modernization of the existing fabric. As a matter of fact, this program was a voluntarist policy which allows focusing on export-oriented growth drivers or the so-called the "World Trades of Morocco" (WTM), mainly: services' offshoring or relocation, automotive sector, electronics, aeronautics, agribusiness, seafood products' processing and the Textile and Clothing sector.

All of these projects and the impacts that are mentioned above were - according to EP - tributary when it comes to competitive modernization of the already existing economic fabric. This is the second pillar of the emerging strategy.

This second pillar of the emerging strategy presents a roadmap for growth that can restore visibility, trust and mobilization. Furthermore, there is an attempt to provide Morocco with an Economic Recovery Program to make it an investment, a production and an export platform. However, a tremendous question remains, and it's the following: Have we really prepared the transition to a modernized and creative economy?

\section{2- The NPIE, complementary contributions and novelties}

From 2005 to 2009, telecoms progressed, infrastructure improved. Many companies have settled in Morocco mainly in sectors with a strong technological component such as aeronautics, electronic components, teleservices ... which urges us to question the contributions of the NPIE in the light of the EP.

NPIE refers to the Public-Private Program Contract (2009-2015) relating to the National Pact for Industrial Emergence and Investment in Morocco. This pact was signed during a ceremony chaired by King Mohammed VI on February 13, 2009 in Fez. Five agreements related to its execution have been signed and concluded between the State (depicted by several representatives) and the private sector (represented by the General Confederation of Enterprises of Morocco (GCEM) and the Professional Organization of Banks of Morocco (POBM)).

The PNEI had 111 measures of which 48 relate to the competitiveness of enterprises. The objectives / impact (by 2015) targeted by the NPIE emerged to give greater visibility to economic actors in a "disturbed international situation"; to reduce urban unemployment rates and the trade deficit; to increase industrial GDP; to support the national and foreign industrial investment; and to contribute to the policy of spatial planning (emergence plan Morocco - 2005).

Five agreements related to the execution of the Program Contract were signed, and they are as follows:

$>$ The first one: is related to Integrated Industrial Platforms or "P2I";

$>$ The second one: is related to the World Trades of Morocco (WTM);

$>$ The third one: is concerned with the competitiveness of SMEs;

$>$ The fourth one: is related to "Training", its importance and its strategic nature;

$>$ The fifth one: is concerned with the establishment, management and development of the Institute of Aeronautical Crafts of Casablanca - IACA.

For the business climate, the plan stipulates that the targeted actions that are corresponding to the needs of investors are: "the greater use of mediation and arbitration for conflict management, harmonization and the continuous improvement of investor reception tools mainly the IRCs and the Moroccan Agency for Investment Development, and the establishment of complete single-sites within the Integrated Industrial Platforms (P2I). Thus, the objective is to improve Morocco's position in international rankings, particularly in "Doing Business" (Eddenani, 2008).

Morocco is reviving, somehow, their 2005 "dreams". The economy is more or less sound, less dependent on agriculture and the services have progressed. However, the growth remains subdued. The rate of growth is insufficient for an economic "take-off", especially for a country whose unemployment rate still exceeds $9 \%$ (Mohammed Lahlimi, Director of the Planning High Commission). There was also an aggravating factor, caused by the failed exports, insufficient diversification, and high value-added products. The trade deficit is growing dangerously especially for the trade of the goods and the deterioration of the income of the Moroccans residing abroad (MRE).

On the one hand, the emergence plan reflected an economy through accessing the logistics proximity markets with the EU and having a medium-skilled workforce. On the other hand, there is a set of pitfalls aggravated by the free trade agreements, the interesting productivity gap, the cost of energy, the quality of the administration, the narrowness of the internal market, business regulation, and taxation.

\section{3- Industrial Acceleration Plan (IAP)}

This plan, launched in 2014, recognizes the contribution of the two previous models and seeks to "consolidate the gains". That is to say, this is based on tangible achievements related to "the $22 \%$ increase in industrial exports, a clear infrastructure evolution and the establishment of global industry leaders, increasing FDI to an 
average annual rate of $23 \%$ since 2009" ( MCINTIC - 2009). The Minister of Industry believed that these performances "have made it possible to better position Morocco on the radars of the planet as a credible and competitive industrial destination". To what extent will the IAP concretize then these ambitions?

The cited objectives do not go beyond the scope of emergence, they are the following: to increase the industry's, to boost quantitatively and qualitatively export capacity, to improve the reception capacities of investors and to increase productivity through targeted support to the industrial fabric. The particular cited components are more concerned with industrial ecosystems for a more integrated industry, support tools adapted to the industrial fabric, a stronger international positioning and steering, and governance of the strategy.

Through reviewing the above-mentioned plans and strategies, we emphasize on the importance of the declared reforms and the diversity of the underlying restructuring measures. However, the already mentioned voluntarism must not make us forget a still worrying reality. We have three main conclusions: the first one is that the industrial base is very fragile because of its high level of fragmentation and the relativity of the impact of the upgrade. The second one is that distinctive comparative factors and advantages are poorly used. Finally, the third one is that sector trends remain favorable despite the rise of Asia, but unless it provides /provided a targeted and proactive approach.

The objectives of the emergence sphere - first and second version - remain far from being achieved. But what about the spatial and territorial expression of the productive system in Morocco especially with the new regionalization project in the making?

\section{Spatial and territorial expression of the industrial movement}

Morocco has not experienced pure and hard taylorophordism, but at the level of the productive structures, the crisis of this issue appears as that of the great dimension and the process of spatial concentration of the production. Such a situation leads to new development models, to new post-Ford production systems, it also has important effects on the spatialization of productive systems.

Similarly, the restructurings that occur at the level of the productive structures bring about a real dynamics of the territories. In addition, after focusing our attention on the evolution of productive structures, we will concentrate on the dynamics of territories that the evolution of the productive system (s) of Morocco from industrial zones to clusters and ecosystems innovation through integrated industrial platforms.

\section{1- industrial zones before the "emergence era", and the willingness to support local economic development and to influence regional imbalances}

Given the role of industry and the weight of spatial and productive restructuring both at national and international level, Morocco needs to be interested, even before their independence, in the importance of infrastructures for hosting productive activities. In fact, their implementation is a major concern in the process of strengthening the global economic environment and the foundations for its viability. The first planned forms of organization of these spaces refers to the notion of "industrial zone" whose national program of industrial zones (NPIZ) claims to be an important notion in Morocco (Sefrioui, 2003).

The NPIZ emerged in 1951 (Ecochard-1951) and was settled in 1980. This was implemented in order to establish a better distributed industrial development and thus fight against the glaring spatial disparities. The NPIZ is more concerned with a set of sites across the different regions of the country with a budget of 950 million dirhams for the development of 1300 ha (Benaceur-1993). In the early 90s, this area has been enlarged to 2000 ha. Thus, from 25 industrial zones in 1980, the NPIZ covered 80 zones at the end of 2001 to reach about 120 in 2004 (mcinet-2004).

The enlargement of the NPIZ is a major factor in the development of the economic role of the local communities for which these areas are essential sources of tax revenues (El Merghadi - 1993). By making a closer diagnosis of this program, it appears that the regional disparities, against which it was initially conceived, are only getting worse and that almost all Moroccan industrial zones suffer from several handicaps, mainly:

- The lack of a real strategic vision in industrial and / or territorial planning;

- The lack of planning and industrial management capacity among the main developers. These developers confound industrial development operations and those of housing subdivision which are devolved to them and to which they are generally accustomed (Sefrioui - 2003);

- The lack of financial means that result from the austerity that is required under the SAP framework and which coincided with the emergence of the NPIZ;

- The fact that the local communities conceive the IZ only in their sources of tax revenue, hence the lack of appropriate management structures and management of industrial space in these communities...

Essentially, the industrial zone was most often apprehended according to the legal and land problems that it arouses; its impact on location ratios; and the effects it has on the functioning of the urban organism. However, it is no longer a reserved space for a specific activity or a simple urban planning technique, but more of a privileged instrument of economic and spatial strategies (Kaioua, 1993). 
Thus, the industrial zone is considered an essential support point for the application of space and sectoral policies carried out by the public authorities. Each actor sees a particular aspect. As a matter of fact, for the company, the industrial zone has the possibility of benefiting as much as possible from the allocation of public aid, particularly in terms of land costs and suppliers. For SMEs, the industrial zone essentially enables the minimization of the implementation costs, the benefit from the presence of certain services and the finding of outlets through specialized subcontracting activities. For the planning organism, the industrial zone acts primarily as an instrument of spatial coherence (El Merghadi, 1993). At the level of the local community, the industrial zone is both an urban planning instrument and an instrument of social and economic development. It conceived as a way of rationalizing urban land use, controlling land speculation and protecting the environment. It is also considered a tool of attracting businesses for job creation and securing new financial resources.

The question of industrial zones has currently been raised between two sorts of concern: firstly, industrial decentralization that is able to boost the economic fabric at the level of different regions. Then, the organization of the urban space and the development of the city proper. In both cases, there is a need to optimize infrastructure investments made by the state for "social and spatial equity".

At the institutional level, the implementation of the above-mentioned programs required the establishment of an orientation and assistance committee chaired by the Prime Minister and an implementation monitoring committee that brings together the ministries of the interior, trade and industry, housing, etc. This institutional framework called for a number of actors / developers who can be public, semi-public or private (Benaceur, 1993). What were, then, the objectives of NPIZ and who are the actors?

\section{1-1. Objectives of the NPIZ}

With the socio-spatial disparities of the 1980s and especially the legacy of the past, the preparation of an integrated space / platform that delivers a kind of diversified panel of infrastructures for the implementation of industrial projects was of primary necessity. The NPIZ had the following objectives:

- Reducing the dependency links between the regions of the same city and the region vis-à-vis other regions;

- Improving the standard of living of the population through distributed income;

- Using the potential of the region by valuing them on the spot;

- Improving the standard of living of people by keeping them at their places;

- Alleviating the crucial problem of unemployment and underemployment in some cities;

- Giving companies technical assistance tailored to their needs and granting them support services for the implementation of projects;

- Making available to the units modular structures adapted to the activities.

Ultimately, the NPIZ aims in principle at enhancing strategic economic and spatial planning. The industrial zone is increasingly conceived as the act of implementing economic activities and coherent spatial planning at the urban scale (Kaioua, 1993).

This program aspires to provide space support to certain units that allow them to be quickly operational.

This asserts that the industrial zone is a privileged means to foster the economic fabric of the city and its region. The objectives presented above are not final and statistical. In fact, these must be evolutionary and must take into consideration the restructuring of the general economic context (Braconnier, 2001). Attaining these objectives of planning; urban planning; economic, social and spatial development identifies broad and different areas of intervention. These latters involve a variety of stakeholders that can be private, public or semi-public.

\section{1-2. The institutional framework of the industrial zones and the diversity of their actors}

The complexity of the missions, devolved to the industrial zones and the diversity of the actors mobilized to ensure the implementation of the objectives, aimed at leading the managers to improve an institutional framework which is capable of guaranteeing the execution and the follow-up of the program. The management and the set up administrative bodies are the Guidance and the Assistance Committee; the Accreditation Commission for Industrial Zones: the Local Award Commission and the Monitoring Committee that is responsible for implementing the program.

From this institutional framework, it is deduced that the development of industrial zones brings together a set of social actors each one of them fulfills a specific function in the planning process (Troin, 2002). The State, the local authorities, the landowners, the development agent, the financing organizations, the industrialists ... are actors who intervene all in the matter of planning of the industrial zones. However, these actors may be sometimes contradictory, which makes the development process particularly complex (Sefrioui, 2003).

These different actors are linked with several reports that escalate during an operation to develop an industrial area. However, the central role always falls to the developer, who occupies a privileged place as the interlocutor vis-à-vis the other actors (Braconnier, 2001).

The developer is not a unique status; it can be a public, a semi-public, or a private body. It can be a chamber of commerce and industry or a mixed economy company (e.g. the French case). However, in Morocco, the 
planner or the developer can be: the CDG, the municipalities, the ERAC, the ministry of the equipment, the direction of the rural affairs or a private company.

Whether the developers are institutional, public, private, or semi-public, they are responsible for:

- land acquisition and registration;

- the subdivision of the area according to a specific parcel plan;

- the equipment of the area;

- allocation of beneficiaries' subdivisions ;

- management or support to the managerial structures of the area.

A review of industrial zones shows that planning still remains the prerogative of the public. What the industrial zone consists in making available to the industrialists land already developed in infrastructures and other basic equipment at preferential prices according to the regions, shows that the spatial dynamic is far from being dictated directly by that of the capital. The dynamics of space and territory, which are elsewhere governed by the organization and logic of the restructuring of productive systems, remains in Morocco a work of the state with the emergence sphere (Eddelani, 2014).

\section{2- P2Is, Clusters and Industrial Ecosystems, Beyond Spatial Expression}

Before dealing with P2Is, let's focus on the concept of industrial parks and their relationship with the processes of regionalization, integration and territorialisation of the act of producing and investing.

\section{2-1. Industrial parks / means of the SME / FMN synergies region-vector}

Today's globalization is raising regionalization. In fact, regionalization is considered "an institutional form of reorganization of relations between the States that is the territory" (Guerraoui, 1998); it is an engine of national and international dynamics.

Thus, because of its median position, the economic region is at the heart of a plurality of logics and at the crossroads of several dynamics linking the local to the regional, the latter at the national level and the rest at the international level.

The region, as it is now claimed in Morocco, is no longer just this space that reinforces the decentralization and deconcentration and gives a sign of the completion of the building of a "modern state"; it is, especially, a region that allows a reflected territorialisation of the productive systems and a local / international synergy. The construction of an economic region in Morocco is uplifting because it is induced by "the structural requirements related to the positive articulation between the consolidation of the national economic space and the development of interregional and continental economic spaces" (Zeriouli, 1996).

Having adhered to the "global village" where borders tend to abolish, Morocco is obliged to prepare a reception structure for foreign investments and national investments, which are able to launch international networks.

Among the undertaken actions and beside the promotion of development poles, industrial zones and the promulgation of investment codes, a policy of industrial development of the territory is necessary (Tarik - 1981). In fact, the center of economic decision-making also involves the development of an integrated, diversified, decentralized and open onto the outside regional productive system. Sefrioui (2003) also believes that: "In the new context of globalization and liberalization, the industrial parks are presented as an important vector for the revitalization of the industrial sector and its bases of competitiveness on a global scale" (p. 128).

Industrial parks are a new formula of spatial organization of industrial systems which allow a successful management for the State, developers (or planners ) and investors.

The main principle of this notion is the following: the developer is supposed to rent lands from the government to sublease them to private companies after their development. The State, here, is in charge of carrying out all the off-site infrastructure and urging the developer to mobilize the private financial funds for the realization of the infrastructures within the site and to ensure the management and the services to the companies. These off-site works concern the water and electricity supply, the sewerage system and the treatment plant.

Thus, the developer needs to act as an intermediary between Moroccan companies and local and national authorities in various fields.

Similarly, a first phase of the Private Industrial Parks Program, developed and managed by organizations with internationally recognized experience in the field, was launched in mid 1997. While conceiving and linking multinational contractors to local subcontractors or partners, well-organized and managed industrial parks will constitute development poles for a successful opening up of the global production system.

This is a difficult task that can only be successful with the support of the State, and above all, the regions through program plans that are capable of boosting regional development and thereby promoting a national economic take-off. The regions that have just been mentioned are those which are able to create synergies at the productive and territorial levels (Kaioua, 1993).

This is why, it is believed that the problem of economic regionalization and land use planning is at the crossroads of many paths. A region that can overcome the challenges of globalization and address its challenges 
would be also able to:

- contribute to the building of an economic, social, spatial and territorial democracy;

- to achieve a rational and intelligent opening on the regional, global and supra-national productive systems;

- $\quad$ create and maintain a harmony between the rural and the urban;

- $\quad$ succeed in creating and maintaining a synergy between SMEs / SMIs (which can also become actors in regional development and not only passive under-treatment) and multinational firms whose powers tend to outweigh those of the States.

In the beginning of the 21st century, Morocco needs an "economic region" that is capable of mobilizing local and regional resources and implementing them for a better integration of the country into the world economy while preserving the competitiveness of the national economy. Will we succeed this work with the P2Is?

\section{2-2. P2Is - Clusters- Ecosystems: Prolongation or Reform?}

If under the aegis of the emergence plan and the NPIE, the P2I was evoked; then, with the IAP, the notions / forms of "clusters" and industrial ecosystem are introduced.

P2Is: can identify with new forms of spatialization of industrial and productive organization in Morocco such as technopoles, clusters and SPLs. The P2I program includes three types of platforms: General P2I open to all sectors, and can combine several sectoral headquarters. Sectoral P2Is serve a specific sector, they may, however, include quarters reserved for sectors close to the main sector (e.g. Electronics district embedded in a P2I Automobile). And finally, the P2I Regional / National Quarters or generalist areas which are reserved for actors of an industrial fabric that come from the same region of a foreign country.

The selection of the final P2I implementation sites is based on the presence of a labor area that ensures an available workforce meeting the needs of industry, logistical accessibility which ensures a good connection of the site for its supply and export of production and in terms of the presence of a mobilisable land reserve.

According to the P2I website, the value offered to investors can take six complementary forms. In fact, it can be the real estate offer (rental or purchase of land or buildings), offering various services (maintenance of infrastructure, security, telecom, catering, health services, bank, business center, support to recruitment, travel agency, etc), training offer (specialized training institute or 'OFPPT'), logistics offer, 'one-stop shop', logistical connectivity to the city and status of free zones for P2I of Kenitra, Nouaceur, Tangier and Oujda (Ministry of Finance, 2012).

Clusters: These are structures that are based on mixed public / private governance which comprises several actors, including the State, large companies, SMEs, educational and research operators, aid and financing organizations with the aim of finalizing the emergence of innovative projects. In 2014, "Morocco Cluster" was created. In fact, its legal status is still not precise, but its thirteen members are based in various regions and operate in various sectors, among others. They are as follows: ICT (Morocco Numeric Cluster), and electronics and Mechatronics (Electronic Cluster, Mechatronics and Mechanics of Morocco - EC3M). The valorization of the products of the sea (Tan-Tan Oceanopole Cluster) and (Agadir Haliopolis Cluster). Luxury products in the food and cosmetics industry (Menara Cluster of Marrakech). Technical textiles (Textile clusters for technical use). Denim fabrics (Cluster denim \& casual wear). Building materials and energy efficiency in Settat. Solar technologies (Solar cluster). Environment and sustainable development in Casablanca. Bio-technologies and agro-industry in Meknes. The Smart City (Smart City Cluster in Casablanca) and the Smart City and the Green Economy in Oujda. This list will certainly be extended to new projects recently installed or in progress such as Tangier tech, etc.

Industrial Ecosystems : This is a new designation of territorialized forms of industrial production that aims to reduce sectoral fragmentation by promoting the establishment of targeted and mutually beneficial strategic partnerships between industry leaders and SMEs (Very Small, Small and Medium enterprises). These ecosystems act as a means to radiate a community of companies of various sizes around a "locomotive" carrying ecosystems projects, and to join all the actors concerned by innovation and creativity.

We need to bear in mind that the projects that were previously developed are very promising in terms of "declaration of intent". However, do we have the material and human resources to ensure a spatially equitable distribution? Should we not mix up clusters, LPS, P2I with a kind of territorial plans of economic cooperation to establish a model of Productive Systems Equitable Socially and Spatially: "PSESS".

The Kingdom of Morocco provides industrial investors with attractive reception areas. This cartography allows you to discover the different industrial zones throughout the kingdom, to identify lots of land or buildings corresponding to your needs. Once you have identified the land you can express your interest directly to the developer who will take care of your file (http://www.zonesindustrielles.ma/map). The main results of our investigation correspond to different forms on the map with here top the link.

\section{Conclusion}

In order to take into account a certain correspondence between the evolution of the productive systems and the 
restrictions of the territories, a general grid can be presented. Three highlights of such an evolution aroused, they are: pre-Fordism, taylotofordism and post-Fordism. It is also taken into consideration the complexes of workshops and factories of the 19th century and the regions of Fordist mass production and the rising of the local through the SPL and the current phenomenon of "glocalization".

Without going back to the controversy related to the opportunity to appeal to foreign firms (particularly Mc Kinsey) and the reconsideration of the national competence in this matter, it is important to recognize the contribution of the emergence program as a diagnostic analysis of the country's economy. In fact, some analysts speak of "ant work", others of interference and waste but there an emphasis on the fact that the EP presents a cross-sectional vision of what our economy is ; especially that an effective therapy requires a good and fine diagnosis on board.

In the same vein, the current Moroccan Minister of Commerce and Industry recognizes that the current issue dictates the following considerations:

- Dynamically manage the existing fabric and respect the balances;

- Come out of the defensive and restrictive logic that underpinned the approach of upgrading the Moroccan economy (MAN);

- Revitalize and modernize the fabric by redesigning the existing device;

- Accelerate long-term cross-cutting reform projects;

- Allocate resources in line with issues and priorities.

This is what the specialized media is more or less aware. Indeed, "for the Emergence program to succeed, it is not enough to provide benefits and train the workforce. There is also a need for general coordination that involves several actors, including five ministerial departments, the "wilayas" and the project facility regions, the regional investment centers, the investment department, the inter-ministerial investment commission, territorial governments and local authorities and local communities. To entrust the task to a single ministry would be utopian. Thus, the idea is to set up a dedicated body in the form of an agency "(Agoumi and Benmansour- 2009).

Improving globalization requires getting involved in the digital sphere and attracting outsourcing activities of services (processing of financial, accounting, and banking information or tele-services). However, the real economy (mainly industrialization) remains the only leader in the dynamic transformation of productive and spatial structures. This is to say, the productive system mainly focuses on the territorial morphology and the spatial rationale recommends the productive activities.

This has to do with the spatial evolution of the Moroccan territorial position linked to its productive system. In fact, the "independent" Morocco transposed - at least at the level of the discourse - industrial districts, industrial zones and industrial parks that consolidate the integrated industrial platforms or P2I whose designation attests to "modernity". It remains unexplained whether this dynamism will be a continuity or simply serve as marketing map for the current government era. This question helps us understand that the productive and spatial dynamics must rhyme with the new dynamics of institutional reforms in favor of a more advanced vision of regionalization. In fact, "the expected enlarged regionalization is not a simple technical or administrative development. Rather, it reflects a resolute option for the renovation and modernization of state structures, and for the consolidation of integrated development. Regionalization will not be balanced and will only be national in scope if the optimal exploitation by each region of its own strengths and potentialities is correlated and concomitant with the establishment of efficient mechanisms of solidarity, embodying complementarity and interregional cohesion in a united Morocco ". (Royal speech, January 3, 2010)

\section{Bibliography:}

$>$ Belal, A. 1976, investment in Morocco, Maghrebian Editions, Rabat.

$>$ Benaceur, O. 1993, The role of local authorities in the industrial zones' development, DHS (D.E.S in french), National Institute of Planning and Uranism (INAU), Rabat.

$>$ Bouinot, J. 2003, The Smart City, Editions : LGDJ, Paris.

$>$ Braconnier, B. 2001, Local actors and tourism development issues in Zagora, Master's thesis in geography, University of Tours.

$>$ Department of Studies and Financial Forecasts (DEPF), January 2010, "Regions of Morocco: Sectoral Contributions to the Creation of National Wealth", Publications of the Moroccan Ministry of Finance, Rabat.

$>$ Ecochard, M. 1951, the industrial districts of the cities of Morocco ", Urbanism Review N 11-12-1951.

$>$ Economic, Social and Environmental Council (ESEC): https://fr.slideshare.net/oumaimakarim1/marocplan-emergence

$>$ Eddelani, O. 2008, Cluster : innovation ecosystem and incubator of competitive organizations and smart territories, case of the Fès-Boulemane region", ASRDLF symposium, August 25- 27, Rimouski, Canada. In : http://asrdlf2018.com/sites/default/files/programme_asrdlf_v14.pdf

$>$ Eddelani, O. 2014, Globalization, productive and spatial restructuring, what prospects for Morocco, 
Edition Presses Académiques Francophones "PAF". (Livre)

$>$ El Merghadi, M. (and al), 1993, Economic interventions of local authorities, proceedings of the symposium organized at the Law Faculty of Fez, law and economics magazine, $\mathrm{N}^{\circ} 9$ - 1993. (organised February 7th \& 8th 1993, at FSJES- USMBA)

$>$ Fadel Agoumi et Saâd Benmansour, In : lavieeco.com, visité le 14-02-2009

Fisher. A, "competitiveness refers to location", In: RERU, 1998.

$>$ Guerraoui, D. 1998, Prospects of an integrated regional development", Economic Views, N ${ }^{\circ} 10-1998$ GPM, Morocco.

$>$ Kaioua, A. 1993, Production and management of industrial zones : the case of Greater Casablanca.Economic interventions of local authorities, Review of Law and Economics, Fez, No. 91993, Pp : 161-178.

$>$ Ministry of Finance and Privatization website: https://www.finances.gov.ma/Docs/2012

$>$ Ministry of Industry, Investment, Trade, and the Digital Economy, 2017, Industrial Acceleration Plan, http://www.mcinet.gov.ma/fr/content/plan-d'acceleration-industrielle

$>$ Morocco Digital Cluster report, 2014, http://www.marocnumericcluster.org/

$>$ Scott A J and M. Storper, "Regional Development" In: Vues Economiques, N ${ }^{\circ}$ 10-1998.

$>$ Sefrioui, F. 2003, Company Morocco. Performance and vulnerability thresholds of the industrial production system at the time of globalization, L'Harmattant Edition.

$>$ Tarik, E. 1981, "Infrastructure and development in Morocco" Edition. Stouky.

$>$ Tarondeau. J. E., Industrial Strategy, Vuibert Edition, January, 1993.

$>$ The Minister of Industry-Trade and ICT at the presentation of the IAP to King Mohammed $6^{\text {th }}$, In http://mcinet.gov.ma.

$>$ Troin, J. F. 2002, Morocco - Regions, countries, territories, Editions Tarik, Casablanca

$>$ Veltz P., Globalization Cities and Territories, Edition, Presses Universitaires De France, 1996.

$>$ Website of the Ministry of Industry in its section devoted to the industrial acceleration plan: http://www.mcinet.gov.ma/fr/content/plan-d'acceleration-industrielle

$>$ www.mcinet.gov..ma, retrieved on March, 14, 2004.

$>$ Zeriouli, M. 1996, Edification of the economic region, Rabat 